\title{
A Study on Safety and Risk Assessment of Dangerous Cargo Operations in Oil/Chemical Tankers
}

\author{
Cenk ŞAKAR, Yusuf ZORBA \\ Dokuz Eylül University, Maritime Faculty, Turkey \\ cenk.sakar@deu.edu.tr; ORCID ID: orcid.org/0000-0001-5821-6312 \\ yusuf.zorba@deu.edu.tr; ORCID ID: orcid.org/0000-0002-5535-5971
}

\begin{abstract}
The safety and risk assessment of dangerous cargo operations in oil and chemical tankers is a necessary process to prevent possible accidents during these operations. Fire and explosion are the major accidents encountered in tanker operations. In this study, a model was constructed through the Fuzzy Bayes Network Method for the probabilistic relationships between the causes of fire and explosion accidents that could occur during the tank cleaning process. The study is composed of two stages. Firstly, the variables that are the subject of the problem and that constitute the graphical structure of the Bayes Networks are identified. Then, expert opinion was sought as the statistical data on accident reports were not recorded properly while identifying the conditional probability of the relationships between the variables. Linguistic variables whose fuzzy membership functions were identified were used in detecting the probabilities. The findings of the sensitivity test revealed that the major reasons that could lead to fire and explosion during the tank cleaning process are ignition sources, reaction and safety culture.
\end{abstract}

Keywords: Bayes Networks, Fuzzy Logic, Risk Assessment, Tanker.

\section{Petrol/Kimyasal Tankerlerde Tehlikeli Yük Operasyonlarında Emniyet ve Risk Değerlendirmesine Yönelik Bir Çalışma}

\section{$\ddot{O} z$}

Petrol ve kimyasal tankerlerde gerçekleștirilen tehlikeli yük operasyonlarının emniyet ve risk değerlendirmesi, bu operasyonlar sırasında meydana gelecek kazaların önlenmesi için gerekli bir süreçtir. Yangın ve patlama, tanker operasyonlarında karşılaşılan başlıca kaza tiplerindendir. Bu çalışmada bulanık bayes ağları yaklaşımı ile tanker operasyonlarından tank temizleme sürecinde meydana gelebilecek yangın ve patlama kazası nedenleri arasındaki olasılıksal iliş̧kiler için bir model oluşturulmuştur. Çalışma ana olarak iki așamadan oluşmaktadır. İlk olarak, problemin konusu olan ve bayes ağlarının grafiksel yapısını oluşturan değișkenler belirlenmiștir. Daha sonra ise bu değișkenler arasındaki ilişkilerin koşullu olasılıklarının belirlenmesi sürecinde kaza raporlarına ilișkin istatistiki verilerin yeterli olmamasından dolayı uzman görüşlerine başvurulmuştur. Olasılıkların ortaya çıkarılmasında, bulanık üyelik fonksiyonları belirlenmiş sözel değişkenler kullanılmıştır. Duyarlılık testi ile elde edilen çalışmanın bulgularında, tank temizleme sürecinde yangın ve patlamaya sebep olacak en önemli nedenler olarak ateşleme kaynaklarl, reaksiyon ve emniyet kültürünün olduğu belirlenmiștir.

Anahtar Kelimeler: Bayes Ağları, Bulanık Mantık, Risk Değerlendirme, Tanker. 


\section{Introduction}

Tanker operations may result in accidents that occur due to highly ambiguous factors like technical problems, human error or organizational deficiencies. Fire and explosion are the major accidents encountered in tanker operations, and they lead to human death, environmental pollution and economic losses. It may not always be sufficient to generate technical and operational solutions to decrease the probability of an accident. The main reason behind this is that the operations in tankers occur in different environmental conditions and thus, technical, human-based and organizational errors may emerge. As a result, it is necessary to develop an efficient safety and risk assessment model in tanker operations.

The major difficulty in safety and risk assessment is randomness, ambiguity and lack of knowledge. Randomness may be defined as lack of cause and pattern in the occurrence of events. Ambiguity, on the other hand, results from insufficient observation, unreliable data or the failures in equipment during measurement [1]. Lack of knowledge manifests itself when the expert does not have enough knowledge to define the relationship between the causes and effects [2]. Fuzzy set theory was developed to overcome ambiguity in risk analysis [3]. It is of great significance to reveal the cause-effect relationships among dangerous factors in safety assessment. In recent years, Bayes networks method has frequently been used in cause-effect analysis in which knowledge is ambiguous [1]. For example, Pasman and Rogers [4] utilized Bayes networks in the risk assessment studies of liquid hydrogen transport and tank stations. Kabir et al. [1] used Bayes networks in oil and gas pipes safety assessment. In their study, Zoullouti et al. [5] made the risk assessment of operating rooms through Bayes networks. Cockburn and Tasfamariam [6] applied this method in seismic risk assessments. In addition to these fields, Bayes networks method has also been used in the field of maritime where ambiguities are common. Datubo et al. [7] and Ren et al. [3] utilized Bayes networks in the risk assessment of offshore platforms. While Hannien [8] used Bayes networks to prevent maritime accidents, Trucco et al. [9] benefited from this method to make the risk assessment of the organizational factors in maritime transport.

Bayes networks method is very effective in uncovering the relationships between variables in case of ambiguity. In this method, identifying the critical variables while detecting the factors leading to the accident is significant. The method is also effective in terms of obtaining quantitative and qualitative data from various sources and utilizing them. Thus, it provides ease of use in decision making processes especially when experimental data are not extensive [10]. The use of statistical data in risk assessment is a very useful method. No matter how important the data is, it may still not explain the exact cause of the accident. Particularly when historical data regarding the accident is insufficient, expert opinion becomes important to develop the risk model [11]. While making a judgment with high level of ambiguity, experts avoid using definite values in expressing themselves. Fuzzy set theory is commonly used when experts give reliable quantitative information [5].

The aim of this study is to develop a model for the assessment of fire and explosion risks that could occur in ships during the tank cleaning process. To this end, fuzzy Bayes networks method has been proposed for risk and safety assessment by integrating the fuzzy set theory and Bayes networks. Bayes inference was made by integrating verbal variables and fuzzy number-based probabilities. 


\subsection{Bayes Networks}

Bayes networks are graphical models that reveal the probabilistic relationships among variables. In Bayes networks known as Directed Acyclic Graph (DAG), nodes represent variables, while the connections between them represent the relationships between the variables [12].

The relationships between the variables in Bayes network structure are expressed as family relationships. The node to which arrows are pointed is called the Child Node, while the nodes from which arrows originate are called Parent Nodes [9]. For each node in the network, dependence on parents is defined with conditional probability. [1]. Another frequently-used analogy to express the variables in Bayes is the tree analogy. Here, the nodes to which no arrows are pointed and which have no parents are called Root Nodes. Child nodes are named as Leaf Nodes when no arrows originate from them in Bayes network system, the Root Node shows the original cause, while the Leaf Node indicates the final effect [13]. According to this definition, in the Bayes network structure in Figure 1, variable $A$ is the parent of variables $E$ and $B$. In this case, variables $B$ and $E$ are the child nodes for variable $A$. Also, variable $E$ is the parent of variables $D$ and $E$, and variables $B$ and $D$ are the parent of variable $C$. Variables $\mathrm{A}$ is the root node as no arrows are pointed to them. Variables $\mathrm{C}$ and $\mathrm{H}$ indicate the leaf nodes [14].

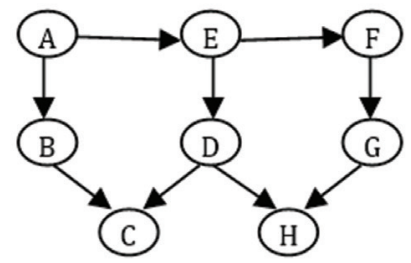

Figure 1. Bayesian Network Structure

In Bayes networks method, which is based on Bayes Theorem, conditional independence is used between the variables in order to overcome ambiguity.

$P(Y / X)=P(X / Y) \cdot P(Y) / P(X)$

In the Bayes Theorem formula above, posterior probability is given with the $\mathrm{P}(\mathrm{Y} / \mathrm{X})$ terms on the left of the equation. This situation shows the probability of hypothesis $\mathrm{Y}$ when the effect of $\mathrm{X}$ evidence is considered. $\mathrm{P}(\mathrm{Y})$ term indicates priori probability that could be expressed as the probability of $Y$. In this respect, priori probability may be considered as the subjective view regarding the occurrence of hypothesis $\mathrm{Y}$ based on past experience. Likelihood, which is expressed with $\mathrm{P}(\mathrm{X} \mid \mathrm{Y})$, gives the probability of evidence $\mathrm{X}$ when hypothesis $\mathrm{Y}$ is known to be true. $\mathrm{P}(\mathrm{X})$ term is independent from $\mathrm{Y}$ and is called as normalizing or scaling factor. The Bayes networks method puts forward a methodology that combines subjective views with obtained evidence [15].

The Bayes networks method answers the questions that reveal the cause-effect relationships in "if this happens, what happens" form for the variables in the network structure. Such questions have very effective and flexible use as they can be used to make inferences from effects to causes through upward diagnosis and from causes to effects based on prediction. Furthermore, the network structure makes update possible through new information about variables [1].

\subsection{Fuzzy Sets}

The Fuzzy set theory was proposed by Zadeh [16] in 1965. It aims to remove the ambiguity that people use in their statements during the decision-making process using linguistic variables [1]. It is the extension of classical sets and defines ambiguity through fuzzy numbers and their membership functions [17]. Fuzzy logic enables to reveal the inferences without using mathematical calculations. As in 
classical logic, there is no definite limit in belonging to a set in fuzzy sets, and this belonging is represented with membership degrees [5]. Fuzzy numbers represent the ambiguity in expert opinion with the membership function that takes values between 0 and 1 . Linguistic variables are used to define the ambiguous expressions in natural languages with definite mathematical terms. There are different membership functions in fuzzy logic. The most common and mostly-accepted among these in fuzzy systems are triangular and trapezoid membership functions [18]. Trapezoid membership function is superior in terms of conceptual and operational easiness compared to the other functions and is commonly used in the membership functions of fuzzy numbers [19]. Thus, the membership function mentioned below was used in this study.

$$
\mu_{\dot{\mathrm{A}}}(x)=\left\{\begin{aligned}
0, & x<a_{1} \\
\frac{x-a_{1}}{a_{2}-a_{1}}, & a_{1} \leq x \leq a_{2} \\
1, & a_{2} \leq x \leq a_{3} \\
\frac{x-a_{4}}{a_{3}-a_{4}}, & a_{3} \leq x \leq a_{4} \\
0, & x<a_{4}
\end{aligned}\right.
$$

Defuzzification turns fuzzy numbers into definite values. Bayes networks and propagation algorithms function based on the definite values of priori and posterior probabilities. Thus, fuzzy numbers corresponding to the linguistic variables defined with fuzzy membership functions must be turned into definite numerical values [20]. For transformation from fuzzy numbers to definite numbers, different methods like maximum membership degree, center of area and weighted mean are used [17]. In this study, the center of area method was used to minimize the loss of knowledge and to make more correct analysis. The equation below was used to turn fuzzy numbers into definite numbers.

$$
\begin{aligned}
& \operatorname{defuzz}(\hat{\mathrm{A}}): \frac{\int x \cdot \mu(x) d x}{\int \mu(x) d x}=\frac{\int_{a_{1}}^{a_{2}}\left(\frac{x-a_{1}}{a_{2}-a_{1}}\right) x d x+\int_{a_{2}}^{a_{3}} x d x+\int_{a_{3}}^{a_{4}}\left(\frac{a_{4}-x}{a_{4}-a_{3}}\right) \cdot x d x}{\int_{a_{1}}^{a_{2}}\left(\frac{x-a_{1}}{a_{2}-a_{1}}\right) \cdot d x+\int_{a_{2}}^{a_{3}} \cdot d x+\int_{a_{3}}^{a_{4}}\left(\frac{a_{4}-x}{a_{4}-a_{3}}\right) \cdot d x}= \\
& \frac{-a_{1} a_{2}+-a_{3} a_{4+\frac{1}{3}}\left(a_{4}-a_{3}\right)^{2}-\frac{1}{3}\left(a_{2}-a_{1}\right)^{2}}{-a_{1}-a_{2}+a_{3}+a_{4}}
\end{aligned}
$$

\section{Methodology}

In the tank cleaning process in oil/ chemical tankers, the assessment methodology of fire and explosion risk with the fuzzy Bayes method, which is composed of six stages, is displayed in Figure 2.

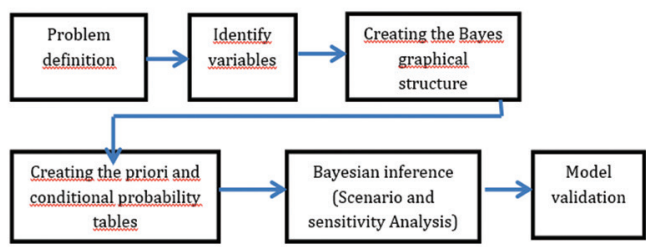

Figure 2. Major Steps in Developing and Analyzing a Bayesian Network

The first stage is identifying the problem and the conditions under which the accident occurred. The next stage is to collect the necessary information in order to reveal the variables that led to the accident. This piece of information may be obtained from accident reports and information databases as well as experts through brainstorming, questionnaires or in-depth interviews. Upon revealing all the variables related to the accident after getting expert opinion, the relationships are discovered for each node representing the variables.

The next stage following the identification of variables, or nodes, is determining the Bayes network graphical structure. The formation of Bayes networks is initiated through the creation of nodes and the graphical network structure that shows the relationship between these nodes. Graphical representation of the network is particularly useful when the relationships between nodes are difficult to express mathematically [21]. At this 
stage, in addition to the formation of graphical structure, nodes and states are defined. When the available information is insufficient in defining the nodes and forming the Bayes network graphical structure, seeking expert opinion is a frequently-used method.

Following the formation of graphical structure of Bayes networks, priori and conditional probability tables must be created for each node. When compiling a conditional probability table, statistical information or expert opinion or both may be used. When statistical information is not enough, expert opinion is mostly sought. However, experts may subjectively be biased especially in forming conditional probability tables in large Bayes networks. In a node with a binary state, the probability assessment of $n$ parent requires $2^{\mathrm{n}}$ condition. In order for the expert not to make a mistake in the assessment of so many probabilities, "decomposition" method is used [22]. According to this method which is based on the study done by Kim and Pearl [23] in 1983, for A node that has parents $\mathrm{B}$ and $\mathrm{C}$, the conditional probability dependent on the parents is approximated to the value below.

$$
\mathrm{P}(\mathrm{A} \mid \mathrm{B}, \mathrm{C})=\alpha \mathrm{P}(\mathrm{A} \mid \mathrm{B}) \mathrm{P}(\mathrm{A} \mid \mathrm{C})
$$

Here, $\alpha$ value is the factor that will normalize the total of conditional probability calculated for each condition of node A to 1 . When nodes have multiple parents, the "decomposition" method helps greatly in forming conditional probability tables by assessing each parent separately.

Every expert may have different views about the probabilities of events depending on their experience and expertise. Here, the important point is reaching a consensus considering expert opinions. Different algorithms are used for this. Aglan and Ali [24] (2014) used triangle fuzzy numbers in combining expert opinion, while $\mathrm{Hsu}$ and Chen [25] (1994) developed a model by using triangle fuzzy numbers together with trapezoid fuzzy numbers [26]. In these studies, each expert was asked to express the subjective features of conditional and priori probabilities of variables using linguistic variables. Modeling the subjective judgments expressed in this way through fuzzy numbers is a commonly-used method. The detailed algorithm that is obtained by reaching a consensus considering all expert opinions is as follows. This approach is known as Similarity Aggregation Method (SAM) [25].

I. Calculating the degree of similarity of the opinions of a pair of experts: If the opinions of $U_{m}$ and $U_{n}$ experts are defined as trapezoid membership functions $\mathrm{U}_{\mathrm{m}}$ $=\left(\mathrm{a}_{1}, \mathrm{a}_{2}, \mathrm{a}_{3}, \mathrm{a}_{4}\right)$ and $\mathrm{U}_{\mathrm{n}}=\left(\mathrm{b}_{1}, \mathrm{~b}_{2}, \mathrm{~b}_{3}, \mathrm{~b}_{4}\right)$, the similarity function of expert $m$ to expert $\mathrm{n}$ is expressed with the formula below. The result is between 0 and 1 , and the higher the value, the stronger the similarity.

$S_{m n}=1-\frac{1}{4} \sum_{i=1}^{4}\left|a_{i}-b_{i}\right|$

II. Calculate Experts' Average Agreement (AA) The Average Agreement degree is defined as:

$$
A A_{m}=\frac{1}{M-1} \sum_{\substack{i=1 \\ n \neq m}}^{M} S_{m n}
$$

III. The calculation of the relative degree of agreement (RA) is done with the formula below:

$$
R A_{m}=\frac{A A_{m}}{\sum_{k=1}^{M} A A_{k}}
$$

IV. Determining expert consensus (Consensus Coefficient). Here, $B$ is known as the optimism coefficient in similarity method and it takes a value between 0 and 1 .. 


$$
C C_{m}=\beta \cdot w_{m}+(1-\beta) R A_{m}
$$

V. Finally, expert opinions are aggregated through the formula below.

$$
E_{A G}=C_{1} \times E_{1}+C_{2} \times E_{2}+\cdots+C_{M} \times E_{M}
$$

The fifth stage of risk and safety assessment is making inferences from the developed model. Following the creation of priori and conditional probability tables, quantitative analysis is done through Bayes network inference. The type of inference depends on the aim of accident analysis. For example, the prediction of the probability of the accident is fulfilled through the priori probabilities. On the other hand, the identification of the contribution of variables affecting the accident is possible through the identification of posterior probabilities [22]. Creation of scenarios and making sensitivity analysis help to make inferences from the developed model. The findings obtained from these inferences are presented with suggestions in order to prevent the re-occurrence of the accident.

The final stage is the verification of the model. Validity is of great significance for the reliability of findings of the Bayes network model. There are different methods in the literature to detect the validity of the model [21]. According to one method that is used commonly to acknowledge the validity of the model, the network structure must verify the following three axioms [21],[22],[27],[28],[11],[29]. This approach was utilized in the current study for the validity of the network structure.

1. A certain degree of increase or decrease in the priori probabilities of each parent node must lead to a relative and significant increase or decrease in the relevant child node.

2. Different rates of increase in the priori probabilities of a parent node must have a consistent effect on the child node.

3. For the child nodes with more than one parent, for example, the mere effect of parent $\mathrm{x}$ on the child node which has parents $\mathrm{x}$ and $\mathrm{y}$ or the mere effect of parent $y$ must be stronger than the effect caused by parents $\mathrm{x}$ and $\mathrm{y}$ together.

3. Safety and Risk Assessment of Tank Cleaning Operation in Oil/Chemical Tankers

\subsection{Identifying the Problem}

When the reports of fire and explosion accidents that have occurred in oil/chemical tankers since the 1980 are examined based on the type of the tanker and the operation carried out by the tanker at the time of the accident, it is seen that more than half of the 77 accidents occurred during tank cleaning or the gas freeing process. When the accidents that occur after unloading are also considered as tank cleaning preparations, this number even gets higher. 217 seamen lost their lives due to such accidents. Expert opinion was sought in order to verify the data that are taken into consideration in identifying the research problem. 22 experts with oil/chemical tanker experience were asked the question "What do you think is the most dangerous process during the operations in oil/ chemical tankers?" in the semi-structured interview format. All the participants answered this question as "Tank Cleaning and Gas Freeing". Thus, this theme was identified as the research problem.

\subsection{Identifying the Variables}

Literature review was conducted in order to identify the variables that lead to accidents during the process of tank cleaning and gas freeing in tankers. As no studies have been found in the relevant literature regarding the causes of fire and explosion accidents that occur during operations in oil/chemical tankers, the accidents that occurred in petrochemical process facilities and tank farms with similar dangers were examined and the 


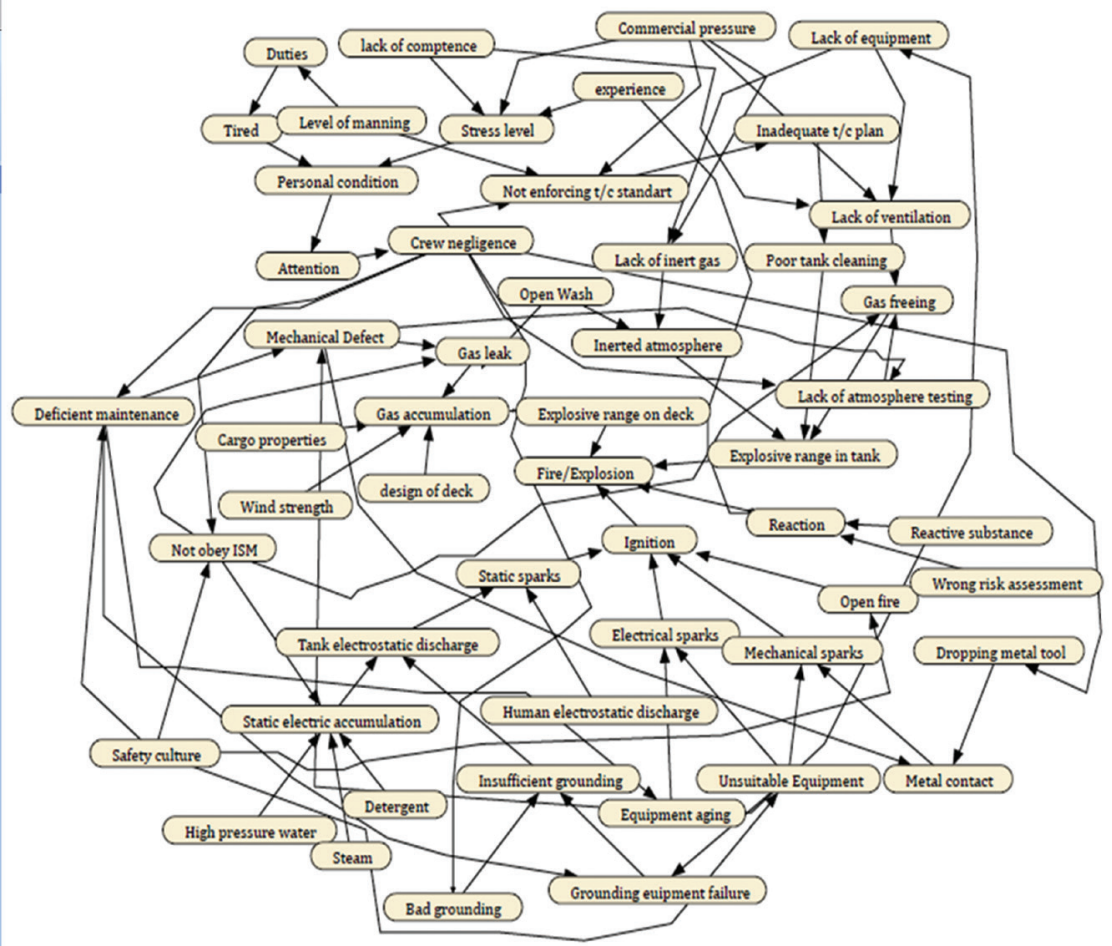

Figure 3. Fuzzy Bayesian Based Safety Assessment Model for Tank Cleaning Operation on Oil/Chemical Tanker

causes of these accidents were reached.

In the next stage, reports of the accidents that resulted in fire and explosion were obtained from international databases and they were subjected to content analysis. 77 fire and explosion accident reports that are in accordance with the conditions specified above were reached and these were used in the current study. The majority of the accident reports were retrieved from Global Integrated Shipping Information System (GISIS) developed by International Maritime Organization. Moreover, the accident reports of European Union and other developed countries were utilized. Following this stage, within the framework of qualitative research process, the variables that emerged as a result of the literature review and the examination of the accidents that occurred due to fire and explosion during the tank cleaning process were updated by getting expert opinion. The agreed variables can be seen in Table 1 .

\subsection{Defining the Nodes and Creating the Bayes Graphical Structure}

Expert opinion was sought to create a pilot Bayes network showing the causes of fire and explosion during the tank cleaning process in tankers and the relationship between them. Experts were asked to express their opinions in two stages. In the first stage, the factors that must be considered in creating the network structure were identified by a group of academicians who are experienced in Bayes network construction. Furthermore, in one-to-one in-depth interviews with people who have worked in oil/chemical tankers for a long time, questions regarding the causes revealed through literature review and accident reports and regarding the other factors that contributed to these causes were asked to the experts. As a result of these interviews, a "pilot Bayes network model" was constructed with the participants. 


\section{Tablo 1. Variables Identified}

\begin{tabular}{|c|c|c|c|}
\hline Variables & Definition & States & \\
\hline Level of Competence & Competence is a combination of knowledge, skills and attitude & High & Low \\
\hline Safety culture & $\begin{array}{l}\text { How the vessel operator and its crew deals with safety } \\
\text { issues }\end{array}$ & High & Low \\
\hline Personal condition & $\begin{array}{l}\text { Indicates whether crew is fit to perform their tasks as tank } \\
\text { cleaning }\end{array}$ & Suitable & Unsuitable \\
\hline Crew negligence & Fail to care enough care or attention to job & Yes & No \\
\hline Experience & Experience of crew for petrol/chemical tanker operations & Adequate & Inadequate \\
\hline Stress level & Indicates stress level of crew & High & Standart \\
\hline Tired & Describing whether crew is tired & Yes & No \\
\hline Duties & Indicates duties of crew in charge for tank cleaning & High & Normal \\
\hline Attention & $\begin{array}{l}\text { Crew's level of attention when performing their tasks for } \\
\text { t/c }\end{array}$ & High & Low \\
\hline Level of manning & Number of crew participating in tank cleaning (t/c) & Adequate & Inadequate \\
\hline $\begin{array}{l}\text { Wrong risk } \\
\text { assessment }\end{array}$ & $\begin{array}{l}\text { Lack of proper risk assessment to identify hazards of } \\
\text { operation }\end{array}$ & Yes & No \\
\hline Lack of atm. testing & Poor testing of hazardous atmosphere & Yes & No \\
\hline Mechanical Defect & Malfunction of equipment & Yes & No \\
\hline Reaction & Indicates likelihood of reaction due to cargo and detergent & Yes & No \\
\hline Open Wash & Tank is open to atmosphere during washing & Yes & No \\
\hline Commercial pressure & $\begin{array}{l}\text { Commercial pressure of charterer/owner to reduce } \\
\text { cleaning time }\end{array}$ & Yes & No \\
\hline Lack of equipment & $\begin{array}{l}\text { Describing capacity of equipment and number of } \\
\text { equipment onboard }\end{array}$ & Yes & No \\
\hline Lack of ventilation & $\begin{array}{l}\text { Indicates insufficient ventilation to remove explosive gas } \\
\text { during t/c }\end{array}$ & Yes & No \\
\hline Reactive substance & Handling of reactive cargo or detergent & Yes & No \\
\hline $\begin{array}{l}\text { Not enforcing } t / c \\
\text { standard }\end{array}$ & $\begin{array}{l}\text { Available guidance and procedure for tank cleaning are not } \\
\text { followed }\end{array}$ & Yes & No \\
\hline Poor tank cleaning & $\begin{array}{l}\text { Insufficient tank cleaning to remove cargo remains from } \\
\text { tank }\end{array}$ & Yes & No \\
\hline Gas freeing & $\begin{array}{l}\text { Describing the way of the removal of explosive gas during } \\
\text { tank cleaning process }\end{array}$ & Right & Wrong \\
\hline Inadequate $\mathrm{t} / \mathrm{c}$ plan & Poor tank cleaning plan before commence operation & Yes & No \\
\hline $\begin{array}{l}\text { Explosive range in } \\
\text { tank }\end{array}$ & Indicates Vapor-air mixtures within explosive range in tank & Yes & No \\
\hline Lack of inert gas & $\begin{array}{l}\text { Using insufficient inert gas to reduce oxygen content (5\%) } \\
\text { in tank }\end{array}$ & Yes & No \\
\hline Inerted atmosphere & Showing oxygen content of tank is below $\% 5$ & Yes & No \\
\hline $\begin{array}{l}\text { Deficient } \\
\text { maintenance }\end{array}$ & $\begin{array}{l}\text { Tank cleaning equipment are not maintained as per } \\
\text { company pms }\end{array}$ & Yes & No \\
\hline Metal contact & $\begin{array}{l}\text { Collision of metal tools and tank walls during tank cleaning } \\
\text { process }\end{array}$ & Yes & No \\
\hline
\end{tabular}


Tablo 1. Variables Identified (Cont')

\begin{tabular}{|c|c|c|c|}
\hline Variables & Definition & States & \\
\hline Not obey ISM & Company ISM procedures are not followed & Yes & No \\
\hline Gas leak & $\begin{array}{l}\text { Describing gas leak to deck from cargo tank during t/c } \\
\text { process }\end{array}$ & Yes & No \\
\hline Gas accumulation & $\begin{array}{l}\text { Likelihood of gas accumulation on deck after releasing } \\
\text { from tank }\end{array}$ & Yes & No \\
\hline Ergonomic design of deck & $\begin{array}{l}\text { Describing the contribution of deck structure to gas } \\
\text { accumulation }\end{array}$ & Suitable & Unsuitable \\
\hline Cargo properties & $\begin{array}{l}\text { Likelihood of gas accumulation on deck in terms of } \\
\text { vapor density }\end{array}$ & Suitable & Unsuitable \\
\hline Wind strength & Wind velocity for gas accumulation & Yes & No \\
\hline Fire/Explosion & $\begin{array}{l}\text { Likelihood of fire and explosion during tank cleaning } \\
\text { process }\end{array}$ & Yes & No \\
\hline Ignition & $\begin{array}{l}\text { Likelihood of ignition due to impact, electrical, static } \\
\text { sparks and open fire }\end{array}$ & Yes & No \\
\hline Mechanical sparks & $\begin{array}{l}\text { Likelihood of mechanical sparks due to equipment that } \\
\text { are used during t/c }\end{array}$ & Yes & No \\
\hline Electrical sparks & $\begin{array}{l}\text { Likelihood of electrical sparks due to equipment that } \\
\text { are used during t/c }\end{array}$ & Yes & No \\
\hline Static sparks & $\begin{array}{l}\text { Potential for development static sparks due to } \\
\text { electrostatic discharge }\end{array}$ & Yes & No \\
\hline Open fire & $\begin{array}{l}\text { The things on deck will cause the spark such as match/ } \\
\text { lighter, hot work etc }\end{array}$ & Yes & No \\
\hline Unsuitable Equipment & $\begin{array}{l}\text { Describing equipment used on tanker whether they are } \\
\text { suitable in terms of standards }\end{array}$ & Yes & No \\
\hline Dropping metal tool & $\begin{array}{l}\text { Indicates dropping metal equipment to tank during } \\
\text { tank cleaning process }\end{array}$ & Yes & No \\
\hline Equipment aging & $\begin{array}{l}\text { Losing properties of equipment depending on the age of } \\
\text { the equipment used in the } t / c \text { process }\end{array}$ & Yes & No \\
\hline $\begin{array}{l}\text { Tank electrostatic } \\
\text { discharge }\end{array}$ & $\begin{array}{l}\text { Describing whether electrostatic discharge is happened } \\
\text { in tank }\end{array}$ & Yes & No \\
\hline $\begin{array}{l}\text { Human body electrostatic } \\
\text { discharge }\end{array}$ & $\begin{array}{l}\text { Likelihood of electrostatic discharge due to friction } \\
\text { between fiber and human body }\end{array}$ & Yes & No \\
\hline $\begin{array}{l}\text { Static electric } \\
\text { accumulation }\end{array}$ & Potential development of static electric in tank & Yes & No \\
\hline Detergent & Describing whether detergent is used or not & Yes & No \\
\hline High pressure water & $\begin{array}{l}\text { Describing whether high pressure hot water is used or } \\
\text { not }\end{array}$ & Yes & No \\
\hline Steam & Describing steam is used or not & Yes & No \\
\hline Insufficient grounding & Inadequate grounding to prevent electrostatic discharge & Yes & No \\
\hline Bad grounding & Describing grounding is done wrongly by crew & Yes & No \\
\hline $\begin{array}{l}\text { Grounding equipment } \\
\text { failure }\end{array}$ & Likelihood of grounding equipment failure & Yes & No \\
\hline Explosive range on deck & $\begin{array}{l}\text { Indicates Vapor-air mixtures within explosive range on } \\
\text { deck }\end{array}$ & Yes & No \\
\hline
\end{tabular}


At the second stage, the aim was to verify the causes of accidents that were obtained before, to update the pilot Bayes network, and to identify the condition of the nodes that will appear in the network structure. At this stage, semi-structured in-depth interviews were conducted with masters who have worked on the tankers of the firms which have played a significant role in oil/chemical tanker management sector. As a result of the interview process, fire and explosion safety and risk assessment Bayes network structure model was constructed using the NETICA (Norsys Software Corp.2006) software as seen in Figure 3 with a full explanation of all variables and their possible states in Table 1.

\subsection{Creating the Priori and Conditional Probability Tables}

Conditional probability tables (CPT) and priori probabilities were created for each node in the Bayes network as a result of expert opinion as the reports on explosions that occurred during the tank cleaning process in oil/chemical tankers are not complete and the reports were not written properly.

For the assessment of the probabilities between the node relationships in the constructed network structure, three experts who worked in oil-chemical tankers and who now work in different departments in firms were identified. The experts are not equal in terms of their positions and experience. Table 2 indicates weighting criteria of different experts.

These experts were selected from among the people who contributed to the construction of Bayes network structure. Considering the fact that the experts may affect each other, each expert was interviewed separately on one-to-one basis. Before the interview, the experts were briefly informed about the aim of the study, the process of revealing the probabilities, and the function of Bayes network structure.
During the face-to-face interview, the selected experts were given some documents showing the meaning and the condition of the nodes whose probabilities the experts would assess. Thus, it was ensured that the expressions and variables that would be asked to the expert could be understood and assessed more easily. Before the interview, questions were prepared to reveal the probabilities that will indicate the strength of the relationship between parent nodes and child nodes. Based on this question format, linguistic variable scale was utilized so that the experts could assess the probabilities.

In probability assessment, for nodes with multiple parents, decomposition method defined section 2 was utilized. In this way, experts did not need to answer too many questions for the same situation, and thus, it was aimed to reach correct results.

Tablo 2. Weighting Criteria of Different Experts

\begin{tabular}{|c|c|c|}
\hline Constitution & Classification & Score \\
\hline \multirow{5}{*}{$\begin{array}{l}\text { Professional } \\
\text { position }\end{array}$} & Academician/SIRE Inspector & 5 \\
\hline & Operation manager & 4 \\
\hline & Safety manager & 3 \\
\hline & Master & 2 \\
\hline & Chief Officer & 1 \\
\hline \multirow{5}{*}{$\begin{array}{l}\text { Sea service } \\
\text { time } \\
\text { (Tanker) }\end{array}$} & $\geq 16$ & 5 \\
\hline & $11-15$ & 4 \\
\hline & $6-10$ & 3 \\
\hline & $3-5$ & 2 \\
\hline & $\leq 2$ & 1 \\
\hline \multirow{5}{*}{$\begin{array}{l}\text { Shore } \\
\text { service time } \\
\text { (Tanker) }\end{array}$} & $\geq 16$ & 5 \\
\hline & $11-15$ & 4 \\
\hline & $6-10$ & 3 \\
\hline & $3-5$ & 2 \\
\hline & $\leq 2$ & 1 \\
\hline \multirow{5}{*}{$\begin{array}{l}\text { Educational } \\
\text { level }\end{array}$} & $\mathrm{PhD}$ & 5 \\
\hline & Master & 4 \\
\hline & Bachelor & 3 \\
\hline & Vocational high school & 2 \\
\hline & School level & 1 \\
\hline
\end{tabular}


Tablo 3. Expert Judgment on Crew Negligence and Conditional Probability Table

\begin{tabular}{|l|l|l|}
\hline CPT & \multicolumn{2}{|c|}{} \\
\hline Crew negligence & & \\
\hline Yes & 0,08 & 0,76 \\
\hline No & 0,92 & 0,24 \\
\hline
\end{tabular}

\begin{tabular}{|c|c|c|c|c|c|}
\hline \multicolumn{5}{|c|}{ Assessment of crew negligence node } & \\
\hline \multirow[t]{2}{*}{ Condition } & \multirow{2}{*}{$\begin{array}{l}\text { Parent node } \\
\text { Attention }\end{array}$} & \multicolumn{3}{|c|}{ Crew negligence } & \\
\hline & & Expert 1 & Expert 2 & Expert 3 & aggregation \\
\hline 1 & High & VL & VL & VL & 0,080 \\
\hline 2 & Low & $\mathrm{H}$ & MH & $\mathrm{H}$ & 0,760 \\
\hline
\end{tabular}

Table 3 shows the conditional probability table sample of the crew negligence node corresponding to each condition of attention node. It was revealed that when the personnel has low levels of attention during the tank cleaning process, the probability of the occurrence of personnel negligence in tank cleaning is $76 \%$. Here, while expressing their ideas regarding the relationship between parent node (attention) and child node (crew negligence), the experts used linguistic variables like "low" or "very high". Each

Tablo 4. Fuzzy Scale

\begin{tabular}{|l|l|}
\hline Linguistic terms & Fuzzy sets \\
\hline Very low (VL) & $(0,0.1,0.1,0.20)$ \\
\hline Low (L) & $(0.1,0.2,0.2,0.3)$ \\
\hline Mildly low (ML) & $(0.2,0.3,0.4,0.5)$ \\
\hline Medium (M) & $(0.4,0.5,0.5,0.6)$ \\
\hline Mildly hidh (MH) & $(0.5,0.6,0.7,0.8)$ \\
\hline High (H) & $(0.7,0.8,0.8,0.9)$ \\
\hline Very high (VH) & $(0.8,0.9,1.0,1.0)$ \\
\hline
\end{tabular}

linguistic variable was defined with fuzzy numbers according to the fuzzy trapezoid membership function as seen in Table 4 .

As the experience levels and interests of the experts are different, the weight factor in Table 5 was used.

To reach a consensus from expert opinions, "similarity aggregation method" developed by Hsu and Chen[25]was used and the opinions were expressed in fuzzy numbers. As definite numbers are needed in Bayes networks, defuzzification was made through the center of area method (equation 3) and the relationship probabilities were obtained as percentages. Table 6 presents the aggregation of expert opinions regarding crew negligence node.

\section{Scenario Analysis and the Evaluation of the Model}

Bayes network enables to define the errors with backward analysis in the developed model as well as making it possible to conduct forward analysis. Thus, it is commonly used in prediction analysis.

Tablo 5. Expert Profile and Decision Weights

\begin{tabular}{|l|l|l|l|l|l|}
\hline No of expert & Title & Sea service & Shore service & Educational level & Weighting score \\
\hline E1 & SIRE Inspector & $6-10$ & $6-10$ & Bachelor & $14 / 41=0,341$ \\
\hline E2 & $\begin{array}{l}\text { Operation } \\
\text { Manager }\end{array}$ & $6-10$ & $11-15$ & Master & $14 / 41=0,341$ \\
\hline E3 & $\begin{array}{l}\text { Safety } \\
\text { manager }\end{array}$ & $6-10$ & $11-15$ & Bachelor & $13 / 41=0,317$ \\
\hline
\end{tabular}


Tablo 6. Aggregation Calculation and Defuzzification for Crew Negligence

\begin{tabular}{|c|c|c|c|c|c|}
\hline Expert 1 (E1) & & 0,7 & 0,8 & 0,8 & 0,9 \\
\hline Expert 2 (E2) & & 0,5 & 0,6 & 0,7 & 0,8 \\
\hline Expert 3 (E3) & & 0,7 & 0,8 & 0,8 & 0,9 \\
\hline S (E12) & 0,85 & & AA (E1) & 0,925 & \\
\hline S (E13) & 1 & & $\mathrm{AA}(\mathrm{E} 2)$ & 0,850 & \\
\hline$S(E 23)$ & 0,85 & & $\mathrm{AA}(\mathrm{E} 3)$ & 0,925 & \\
\hline RA (E1) & 0,343 & & CC (E1) & 0,330 & \\
\hline RA (E2) & 0,315 & & $\mathrm{CC}(\mathrm{E} 2)$ & 0,340 & \\
\hline RA (E3) & 0,343 & & $\mathrm{CC}(\mathrm{E} 3)$ & 0,342 & \\
\hline Weight of expert 1 (E1) & 0,317 & & & & \\
\hline Weight of expert 2 (E2) & 0,366 & & & & \\
\hline Weight of expert 3 (E3) & 0,341 & & & & \\
\hline Aggregation & & 0,640 & 0,742 & 0,776 & 0,877 \\
\hline Defuzzification (COA) & $\begin{array}{l}\text { Under low cre } \\
0,758\end{array}$ & on, oc & ce likeli & rew ne & \\
\hline
\end{tabular}

In forward analysis, the occurrence probability of any node is revealed based on the priori probabilities of root nodes and the conditional independence of each node. In backward inference, on the other hand, the posterior probability of the variables in the network are calculated based on a certain observation or evidence [28].

\subsection{Scenario Analysis}

In order to assess the conformity of the Bayes network model, two hypotheticall scenarios, which are named as best and worst case, were considered in addition to the present situation. 15 root nodes and states in the network structure in these scenarios are given in Table 7.

Following the identification of priori and conditional probabilities by the experts, the present case scenario was run with the Netica software. Here, 22.4\% fire and explosion risk emerged during the tank cleaning operations. This situation points to the fact that tank cleaning during oil/chemical tanker operations is a very dangerous process and if the necessary measures are not taken, the rate of risk may easily increase. The factors that could lead to the increase or decrease in risk level are indicated as nodes in the network structure. First, the best case scenario was taken into consideration to decrease the rate of fire and explosion risk.

In the best case scenario, the favorable conditions of the states of root nodes were considered. Here, as the 15 root nodes in the network structure are the main causes of the other factors that lead to fire and explosion in the tank cleaning process, changes were made in scenario analysis based on these nodes.

As seen in Table 7, when favorable conditions of the root nodes were made (\%100), the risk of fire and explosion in the tank cleaning process is predicted as $9.74 \%$. As for the worst case scenario, this time, the negative conditions of the same root nodes were made $100 \%$. In this inference, the risk of fire and explosion increased to $78.1 \%$. As expected, in the worst case scenario, a 
Tablo 7. Results of Current, Best and Worst Case Scenario used Fuzzy Bayesian Model

\begin{tabular}{|c|c|c|}
\hline & $\begin{array}{l}\text { Best Case } \\
\text { Scenario }\end{array}$ & $\begin{array}{l}\text { Worst Case } \\
\text { Scenario }\end{array}$ \\
\hline $\begin{array}{l}\text { Level of } \\
\text { Competence }\end{array}$ & positive & negative \\
\hline Safety culture & positive & negative \\
\hline Experience & positive & negative \\
\hline Level of manning & positive & negative \\
\hline $\begin{array}{l}\text { Wrong risk } \\
\text { assessment }\end{array}$ & positive & negative \\
\hline Open wash & positive & negative \\
\hline $\begin{array}{l}\text { Commercial } \\
\text { pressure }\end{array}$ & positive & negative \\
\hline Reactive substance & positive & negative \\
\hline $\begin{array}{l}\text { Ergonomic design } \\
\text { of deck }\end{array}$ & positive & negative \\
\hline Cargo properties & positive & negative \\
\hline Wind strength & positive & negative \\
\hline $\begin{array}{l}\text { Human body } \\
\text { electrostatic } \\
\text { discharge }\end{array}$ & positive & negative \\
\hline Detergent & positive & negative \\
\hline $\begin{array}{l}\text { High pressure } \\
\text { water }\end{array}$ & positive & negative \\
\hline Steam & positive & negative \\
\hline Current Condition & Best case & Worst case \\
\hline Fire/Explosion & Fire/Explosion & Fire/Explosion \\
\hline $\begin{array}{ll:l}\text { yes } & 22.4 \\
\text { no } & 77.6 & \\
\end{array}$ & $\begin{array}{ll:l}\text { yes } & 9.74 & \\
\text { no } & 90.3 & \\
\end{array}$ & \begin{tabular}{|ll:l} 
yes & 78.1 & \\
no & 21.9 & \\
\end{tabular} \\
\hline
\end{tabular}

dramatic increase was observed in fire and explosion risk.

\subsection{Sensitivity Analysis}

Sensitivity analysis is a tool that reveals the action pattern of the Bayes network model. It shows how the changes and uncertainties in the network structure function when data about the nodes in network structure is entered. Sensitivity analysis reveals which variable in the model has the biggest effect on the target node, and the variables are ranked in terms of their effects [30]. In other words, with sensitivity analysis, it is understood how sensitive the model is to the changes in the nodes. It is also possible to uncover the inconsistencies in the model through sensitivity analysis [28]. The major approach in this analysis is to find out the effect of the changes in the conditions of the nodes on posterior probabilities [3]. One way of making sensitivity analysis is the backward inference made with the assumption that the target node is realized (\%100). In this inference, a comparison is made between the priori probability values and the posterior probability values, and the percentage of effect on target node and order of importance are obtained [22]. Another method used in sensitivity analysis is the "target node sensitivity analysis" used by Brosnan [31] in 2006. In this method, also named as forward inference, the effect of the changes in each node in the network structure on the target node is examined. Here, each node is entered a piece of evidence, or values, and the effect of each node on the target node is observed through the difference in the changes in posterior probabilities. Consequently, the node with the strongest effect on the target node is found [33].

In this study, target node sensitivity analysis was conducted. As seen in Table 8 , it was assumed that each node in the network structure has evidence. When each node in the network structure occurred separately, its effect on fire and explosion posterior probabilities was calculated one by one. It is observed that the effect of the variables that are close to the target node in the network structure is stronger.

As seen in Table 8, the node with the strongest effect on fire and explosion risk in the tank cleaning process is ignition. The occurrence of ignition probability increases the risk of fire and explosion risk by $28 \%$, from $22.4 \%$ to $50.4 \%$. The second important factor affecting the fire explosion risk is reaction. Although the 
Tablo 8. Mutual Information of Prior and Posterior Probability

\begin{tabular}{|c|c|c|c|c|c|}
\hline & $\begin{array}{l}\text { prior } \\
\%\end{array}$ & $\begin{array}{l}\text { evidence } \\
\%\end{array}$ & $\begin{array}{l}\text { fire/explosion } \\
\text { prior } \%\end{array}$ & $\begin{array}{l}\text { fire/explosion } \\
\text { posterior } \%\end{array}$ & $\begin{array}{l}\text { Change of } \\
\text { probability } \%\end{array}$ \\
\hline Ignition & 33,2 & 100 & 22,4 & 50,4 & 28,0 \\
\hline Reaction & 3,74 & 100 & 22,4 & 48,9 & 26,5 \\
\hline Open Fire & 20 & 100 & 22,4 & 40,2 & 17,8 \\
\hline Safety culture & 19 & 100 & 22,4 & 38,8 & 16,4 \\
\hline Explosive range in tank & 48,1 & 100 & 22,4 & 35,9 & 13,5 \\
\hline Gas freeing & 36 & 100 & 22,4 & 35 & 12,6 \\
\hline Explosive range on deck & 42,1 & 100 & 22,4 & 34,9 & 12,5 \\
\hline Mechanical sparks & 35,4 & 100 & 22,4 & 34,7 & 12,3 \\
\hline Gas leakage & 33,9 & 100 & 22,4 & 33,6 & 11,2 \\
\hline Unsuitable Equipment & 35,6 & 100 & 22,4 & 33,6 & 11,2 \\
\hline Gas accumulation & 36,3 & 100 & 22,4 & 33,1 & 10,7 \\
\hline Not obey ISM & 37,8 & 100 & 22,4 & 33 & 10,6 \\
\hline Electrical sparks & 45,8 & 100 & 22,4 & 32,6 & 10,2 \\
\hline Deficient maintenance & 33,5 & 100 & 22,4 & 32,5 & 10,1 \\
\hline Crew negligence & 33,9 & 100 & 22,4 & 32,1 & 9,7 \\
\hline Tank electrostatic discharge & 35,9 & 100 & 22,4 & 31,5 & 9,1 \\
\hline Lack of atmosphere testing & 35,9 & 100 & 22,4 & 31,2 & 8,8 \\
\hline Static sparks & 40,4 & 100 & 22,4 & 31,2 & 8,8 \\
\hline Grounding equipment failure & 42,1 & 100 & 22,4 & 30,3 & 7,9 \\
\hline Mechanical Defect & 39 & 100 & 22,4 & 30,2 & 7,8 \\
\hline
\end{tabular}

Tablo 9. Validation of Model by Axiom I-II

\begin{tabular}{|c|c|c|c|c|c|c|}
\hline \multirow{3}{*}{$\begin{array}{l}\text { Increase } 20 \% \\
\end{array}$} & \multirow{2}{*}{\multicolumn{2}{|c|}{\begin{tabular}{|l|} 
Parent node \\
Level of competence
\end{tabular}}} & \multirow{2}{*}{\multicolumn{2}{|c|}{\begin{tabular}{|l|} 
Child node \\
Stress level
\end{tabular}}} & \multirow{2}{*}{\multicolumn{2}{|c|}{$\begin{array}{l}\text { Child node } \\
\text { Lack of ventilation }\end{array}$}} \\
\hline & & & & & & \\
\hline & \multirow{5}{*}{ high } & 91 & \multirow{5}{*}{ high } & 25,2 & \multirow{5}{*}{ yes } & 31,2 \\
\hline Increase $10 \%$ & & 81 & & 27,1 & & 34,2 \\
\hline Prior probability & & 71 & & 29,1 & & 37,6 \\
\hline Decrease $10 \%$ & & 61 & & 31 & & 40,9 \\
\hline Decrease $20 \%$ & & 51 & & 32,9 & & 44,1 \\
\hline
\end{tabular}

priori probability showing its occurrence the safety culture. When the safety culture probability in tankers is $3.74 \%$, it leads to of the workers in the firms and vessels a $26.5 \%$ increase in fire and explosion risk if it occurs. is low, fire and explosion risk during the tank cleaning process increases by $16.4 \%$. Another important factor in Table 8 is The other factors leading to an increase in 
the risk are wrong gas freeing, existence of explosive gases on the deck, mechanical spark, gas leakage and the use of unsuitable equipment. Here, the striking finding is that child nodes as well as root nodes have a significant effect on fire and explosion risk.

\subsection{The Validity of the Model}

The three axioms specified in section 2 must be present for the nodes in the network structure. The verification of Axioms 1 and 2 was done as shown in Table 9. Here, the node "competence" is the parent node of the "stress level" and "lack of ventilation" child nodes.

According to Axiom 1, an increase in the priori probability of the parent node "competence" is expected to have a positive effect on level of stress and insufficient ventilation. As seen in Table 9, when a 10\% increase occurs in competence node whose priori probability is $71 \%$, a $2 \%$ and a $3.4 \%$ decrease is observed in the level of stress and insufficient ventilation, respectively. To verify Axiom 2, when an additional 10\% increase occurs in the priori probability of the competence node, then, a $1.9 \%$ and a 3\% decrease were observed, respectively. This means that the effect of the increases that could occur in parent node on the posterior probability of child node is consistent. It was further observed that a $10 \%$ decrease in the priori probability of parent node is proportional to the results revealed.

Table 10 was constructed to verify Axiom 3. As seen in the table, the parent nodes of child node 'lack of atmosphere test' are 'crew negligence' and 'mechanical defect'. Here, the positive and negative effects of parent nodes on the child node (\%100) were initially tested separately. When the probability oflack of crewnegligence is set to $100 \%$, the posterior probability of lack of atmosphere test decreases from $35.9 \%$ to $13.3 \%$. When the probability of lack of mechanical defect is set to $100 \%$ alone, the probability of lack atmosphere test decreases to $17.4 \%$. When two nodes occur at the same time, the probability of occurrence of insufficient atmosphere test is expected to be lower than the separate effects of two parent nodes. As seen in the table, the common effect of two child nodes was found to be $8 \%$. These processes were repeated for the probability of occurrence of negative conditions of the child nodes, and findings validating Axiom 3 requirements were obtained. In other words, the positive effects of child nodes reduce the probability of insufficient atmosphere test, which leads to a decrease in fire explosion risk.

These three axioms were tested for all the child nodes in the Bayes network structure; thus, the validity of the structure was confirmed.

Among the other methods used to verify the Bayes network structure is the comparison of the findings of similar studies or the statistical data [32]. Within this framework, the causes of accidents obtained from accident reports were entered as evidence to the model. 10 accidents involving fire and explosion were run in the network structure and it was

Tablo 10. Validation of Model by Axiom I-II

\begin{tabular}{|c|c|c|c|c|c|c|c|c|c|c|c|c|}
\hline \multirow[b]{3}{*}{$\begin{array}{l}\text { Lack of atmosphere } \\
\text { testing }\end{array}$} & \multirow{2}{*}{\multicolumn{2}{|c|}{$\begin{array}{c}\text { Prior } \\
\text { probability }\end{array}$}} & \multirow{2}{*}{\multicolumn{2}{|c|}{$\begin{array}{c}\text { Crew } \\
\text { negligence }\end{array}$}} & \multirow{2}{*}{\multicolumn{2}{|c|}{$\begin{array}{c}\text { X13 Effect } \\
\begin{array}{c}\text { Mechanical } \\
\text { defect }\end{array}\end{array}$}} & \multirow{2}{*}{\multicolumn{2}{|c|}{$\begin{array}{c}\mathrm{X} 4+13 \\
\text { Effect }\end{array}$}} & \multicolumn{4}{|c|}{ Fire / Explosion } \\
\hline & & & & & & & & & \multicolumn{2}{|c|}{$\begin{array}{c}\text { Prior } \\
\text { probability }\end{array}$} & \multicolumn{2}{|c|}{$\begin{array}{c}\text { Posterior } \\
\text { probability }\end{array}$} \\
\hline & Yes & No & Yes & No & Yes & No & Yes & No & Yes & No & Yes & No \\
\hline $100 \%$ positive & \multirow{2}{*}{35,9} & \multirow{2}{*}{64,1} & 13,3 & 80,7 & 17,4 & 82,6 & 8 & 92 & \multirow{2}{*}{22,4} & \multirow{2}{*}{77,6} & 15,6 & 84,4 \\
\hline $100 \%$ negative & & & 80,1 & 19,9 & 64,9 & 35,1 & 89 & 11 & & & 35,2 & 64,8 \\
\hline
\end{tabular}


observed that accident risk was between $70 \%$ and $83 \%$. This contributed to the validity of the network structure.

\section{Results and Discussion}

The effect of the variables that lead to fire and explosion in the tank cleaning process on each other and the relationship between them were examined with Bayes networks. The proposed model in this study informs the personnel working in tankers and the firms operating tankers about the causes of fire and explosion during the tank cleaning process and the risks posed. When the probabilities of the variables in Table 8 are examined, the most sensitive situations that are open to error during the operation can be described. The effect of variables on fire and explosion risk and the order of importance were revealed through sensitivity analysis. In the safety and risk assessment of fire and explosion during the tank cleaning process, the nodes of ignition, reaction, open fire, safety culture, explosive air/gas combination inside the tank, and the errors in the gas freeing were identified as the major variables that need to be taken into account. Based on the model structure, the measures that must be taken at the first stage to avoid fire and explosion in the tank cleaning process are as follows:

- The elements on the deck that could lead to ignition must be removed before tank cleaning. Measures must be taken particularly to prevent open fire and mechanical spark.

- If the load or detergent that could cause reaction danger involves the possibility of handling during tank cleaning,it must be understood that this process is very dangerous, and a suitable risk assessment must be conducted in order to prevent an explosion that could occur as a result of such an interaction.

- The effect of low safety culture of the firm and the workers on the other factors that lead to fire and explosion must be considered, and the necessary measures must be taken to improve safety culture.

- Asignificant condition for the occurrence of fire and explosion is the existence of explosive gases in the tank and on the deck. The organizational, personnelrelated, and structural factors that could lead to this situation must be taken into consideration.

- ISM procedures must be followed. The necessary measures must be taken to minimize personnel negligence.

Future studies may examine the relationships with the other nodes that contribute to the occurrence of these important nodes that lead to fire and explosion through backward inference method in a more detailed manner. Furthermore, prior to the tank cleaning process in oil and chemical tankers, the reliability of the model may be tested through the real-time implementation of the developed Bayes network model.

\section{References}

[1] Kabir, G., Sadiq, R. and Tesfamariam, S. (2015). A fuzzy bayesian belief network for safety assessment of oil and gas pipelines. Structure and Infrastructure Engineering, 2015:12(8):874-889.

[2] Dolšek, M. (2012). Simplified method for seismic risk assessment of buildings with consideration of aleatory and epistemic uncertainty. Structure and Infrastructure Engineering, 2012:(8):939-953.

[3] Ren, J., Jenkinson, I., Wang, J., Xu, D. L. and Yang, J. B. (2009). An offshore risk analysis method using fuzzy bayesian network.Journal of Offshore Mechanics and Arctic Engineering, 2009:131(4):1-16.

[4] Pasman, H. and Rogers, W. (2012). Risk assessment by means of bayesian networks: a comparative study 
of compressed and liquefied h2 transportation and tank station risks. International Journal of Hydrogen Energy, 2012:(37):17415-17425.

[5] Zoullouti, B.,Amghar, M. and Sbiti, N. (2017). Risk analysis of operating room using the fuzzy bayesian network.InternationalJournal of Engineering, 2017:30(1):66-74.

[6] Cockburn, G. and Tesfamariam, S. (2012). Earthquake disaster risk index for Canadian cities using bayesian belief networks.Georisk: Assessment and Management of Risk for Engineered Systems and Geohazards, 2012:6(2):128-140.

[7] Datubo E, A., Wall, A., Saajedi, A. and Wang, J. (2008). Marine and offshore safety assessment by incorporative risk modelling in a fuzzy- bayesian network of an induced mass assignment paradigm. Risk Analyisis, 2008:28(1):95-112

[8] Hannien, M. (2014). Bayesian networks for maritime traffic accident prevention: benefits and challenges. Accident Analysis and Prevention, (73): 305-312.

[9] Trucco, P., Cagno, E., Rugger, F. and Grande, O. (2008). A bayes belief network modelling of organisational factors in risk analysis: a case study in maritime transportation.Reliability Engineering and System Safety, 2008:(93):823-834.

[10] Jones,B., Jenkinson, I., Yang, Z. and Wang, J. (2010). The use of bayesian network modelling for maintenance planning in a manufacturing industry. Reliability Engineering and System Safety, 2010:95:267-277.

[11] Zhang, D., Yan, X., Yang, Z., Wall, A. and Wang, J. (2013). Incorporation of formal safety assessment and bayesian network in navigational risk estimation of the Yangtze River. Reliable Engineer System Safety,
2013:(118):93-105.

[12] Pearl, J., (1988). Probabilistic reasoning in intelligent systems: Networks of plausible inference. San Francisco: Morgan Kaufmann Publishers.

[13] Korb, K. B. and Nicholson A. E. (2004). Bayesian artifical intelligence. London: Chapman \&Hall

[14] Neapolitan, R. E. (2003). Learning bayeian networks. Upper Saddle River: Prentice-Hall

[15] Lockamy, A. III (2011). Benchmarking supplier risks using bayesian networks.Benchmarking: An International Journal, 2011:18( 3):409-427

[16] Zadeh, L. A. (1965). Fuzzy sets. Information and Control, 1965:8:338353.

[17] Ross, T. (2004). Fuzzy logic with engineering applications (2nd ed.). West Sussex: Wiley

[18] Gedik, N. (2017). Gemilerde ElektroTeknik Zabiti olarak çalışacak kişiler için mesleki yeterlik ölçütlerin bulanık AHP yötemi ile değerlendirilmesi. Journal of ETA Maritime Science, 2017:5(2):140-152.

[19] Kabir, G. and Sumi, R. S. (2014). Power substation location selection using fuzzy analytic hierarchy process and promethee: a case study from Bangladesh. Energy. 2014:(72):717730.

[20] Ferdous, R., Khan, F., Sadiq, R., Amyotte, P. and Veitch, B. (2011). Fault and event tree analysis for process system risk analysis:Uncertainty handling formulations. Risk Anlyasis, 2011:31:86-107.

[21] Rathnayaka, S., Khan, F., and Amyotte, P. (2012). Accident modeling approach forsafety assessment in an LNG processing facility. Journal of Loss Prevention in the Process Industries, 2012:25:414-423. 
[22] Wang, Y. F., Roohi S. F., Hu, X. M. and Xie, M. (2011). Investigations of human and organizational factors in hazardous vapor accidents. Journal of Hazardous Materials, 2011:191(13):69-82.

[23] Kim, J. H. and Pearl, J. (1983). A computational model for causal and diagnostic reasoning in inference systems. Los Angeles: University of California,.

[24] Aqlan, F. and Ali, M. E. (2014). Integrating lean principles and fuzzybow-tie for risk assessment in chemical industry. Journal of Loss Prevent. Process Ind, 2014:(29):3948.

[25] Hsu, H. M and Chen, T. C. (1996). Aggregation of fuzzy opinions under group decision making.Fuzzy Sets and System, 1996:79:279-285.

[26] Lavasani, S. M., Zendegani, M. and Çelik, M. (2012). An extension to fuzzy fault tree analysis (ffta) application in petrochemical process industry. Process Safety and Enviromental Protection. 2012:93:75-88

[27] Yang, Z. L., Wang, J., Bonsall, S., and Fang, Q. G. (2009). Use of fuzzy evidential reasoning in maritime security assessment. Risk Analysis, 2009:29:95-120.

[28] Cai B., Liu, Y., Zhang Y., Fan Q., Liu Z. and Tian X. (2013). A dynamic bayesian networks modeling of human factors on offshore blowout.Journal of Loss Prevention in the Process Industries, 2013:26:639-649.

[29] Sharma P. and Kulkarni, M. (2013). Bayesian belief network for assessing impact of factors on army's lean-agile replenishment system. Journal of Military Studies, 2013:7(1):11-23.

[30] Marcot, B. G. (2012).Metrics for evaluating performance and uncertainty of bayesian network models. Ecological Modeling,
2012:230:50-62.

[31] Brosnan, A. J. (2006). Sensitivity analysis of a bayesian belief network in a tactical intelligence application. Journal of Battlefield Technology, 2006:9(2):33.

[32] Greenberg, R. (2007). A quantitative safety model of systems subject to low probability high consequence accidents. PhD,University of South Australia, System Engineering and Evaluation Centre. 